\title{
Microwave-Assisted Hydrothermal Synthesis and Annealing of $\mathrm{DyF}_{3}$ Nanoparticles
}

\author{
E. M. Alakshin, ${ }^{1}$ A. V. Klochkov, ${ }^{1}$ E. I. Kondratyeva, ${ }^{1}$ S. L. Korableva, ${ }^{1}$ A. G. Kiiamov, ${ }^{1}$ \\ D. S. Nuzhina, ${ }^{1}$ A. A. Stanislavovas, ${ }^{1}$ M. S. Tagirov, ${ }^{1,2}$ M. Yu. Zakharov, ${ }^{1}$ and S. Kodjikian ${ }^{3}$ \\ ${ }^{1}$ Kazan Federal University, Kremlevskaya 18, 420008 Kazan, Russia \\ ${ }^{2}$ Institute of Perspective Research, TAS, L. Bulachnaya 36a, 420111 Kazan, Russia \\ ${ }^{3}$ University Grenoble Alpes, CNRS, Institut NEEL, 38000 Grenoble, France \\ Correspondence should be addressed to E. M. Alakshin; alakshin@gmail.com
}

Received 14 June 2016; Revised 14 October 2016; Accepted 24 October 2016

Academic Editor: Paulo Cesar Morais

Copyright (C) 2016 E. M. Alakshin et al. This is an open access article distributed under the Creative Commons Attribution License, which permits unrestricted use, distribution, and reproduction in any medium, provided the original work is properly cited.

\begin{abstract}
The series of $\mathrm{DyF}_{3}$ nanosized samples was synthesized by the colloidal chemistry method. The microwave-assisted hydrothermal treatment was used for the first time for the modification of $\mathrm{DyF}_{3}$ nanoparticles. Transmission electron microscopy images show that the $\mathrm{DyF}_{3}$ nanoparticles have average particle size of about $16-18 \mathrm{~nm}$ and the size distribution becomes narrower during the microwave irradiation. The X-ray diffraction analysis shows the narrowing of the diffraction peaks versus microwave treatment time. The experimental data demonstrates restructuring of the nanoparticles and their crystal structure becomes closer to the ideal $\mathrm{DyF}_{3}$ regular structure during the microwave irradiation of colloidal solution. The defect-annealing model of the microwaveassisted hydrothermal modification process is suggested.
\end{abstract}

\section{Introduction}

Several dozen research papers dedicated to $\mathrm{LnF}_{3}$ nanosized samples synthesis have been published in recent years. Nowadays the lanthanide fluoride nanoparticles attract scientific interest because of their possible applications in many areas such as lasers, biolabels, and optical amplifiers [1-12]. The autoclave hydrothermal treatment is often used for structure and size modification of the lanthanide nanoparticles. The microwave-assisted synthesis of $\mathrm{PrF}_{3}$ nanoparticles was suggested by Ma et al. [13] and modified at Kazan Federal University (Kazan, Russia). The $\operatorname{PrF}_{3}$ nanoparticles size and structure dependence on the microwave-assisted hydrothermal treatment time were obtained by the high-resolution transmission electron microscopy (TEM), nuclear magnetic resonance (NMR), and electron paramagnetic resonance [1421].

The other trifluoride compound of great interest is $\mathrm{DyF}_{3}$. Recent research showed that $\mathrm{DyF}_{3}$ powders could significantly improve the properties of Nd-Fe-B magnets [22-25]. In addition, $\mathrm{DyF}_{3}$ is an important component of oxyfluoride glasses [26]. On the other hand, there is a ferromagnetic phase transition in a single crystal at $T_{c}=2.55 \mathrm{~K}$ [27]. Investigation of Curie temperature dependence versus the size of $\mathrm{DyF}_{3}$ nanoparticles is a fundamental problem. There are only few reports about $\mathrm{DyF}_{3}$ nanoparticles synthesis [28-30] and the size modification was achieved by the autoclave technique.

The aim of the present work is a synthesis and modification of $\mathrm{DyF}_{3}$ nanoparticles using the microwave-assisted hydrothermal treatment method.

\section{Materials and Methods}

Sodium fluoride $\mathrm{NaF}$ (99.9\%) and dysprosium oxide $\mathrm{Dy}_{2} \mathrm{O}_{3}$ (99.99\%) were obtained from Sigma-Aldrich. The nanosized $\mathrm{DyF}_{3}$ samples \#1-3 were synthesized by similar method as for $\mathrm{PrF}_{3}$ nanoparticles synthesis $[14,15]$. In a typical synthesis, $6.2 \mathrm{~g}$ of powdered dysprosium oxide $\mathrm{Dy}_{2} \mathrm{O}_{3}$ was dissolved in $400 \mathrm{~mL}$ of $10 \%$ nitric acid $\mathrm{HNO}_{3}$ aqueous solution to form a transparent solution

$$
\begin{aligned}
& \mathrm{Dy}_{2} \mathrm{O}_{3}(\mathrm{~s})+6 \mathrm{HNO}_{3}(\mathrm{aq}) \\
& \quad \longrightarrow 2 \mathrm{Dy}\left(\mathrm{NO}_{3}\right)_{3}(\mathrm{aq})+3 \mathrm{H}_{2} \mathrm{O}(\mathrm{l})
\end{aligned}
$$




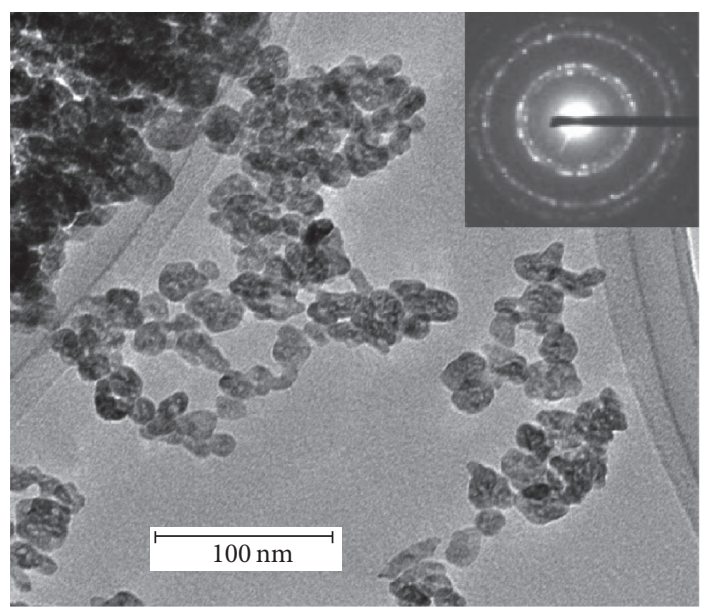

(a)

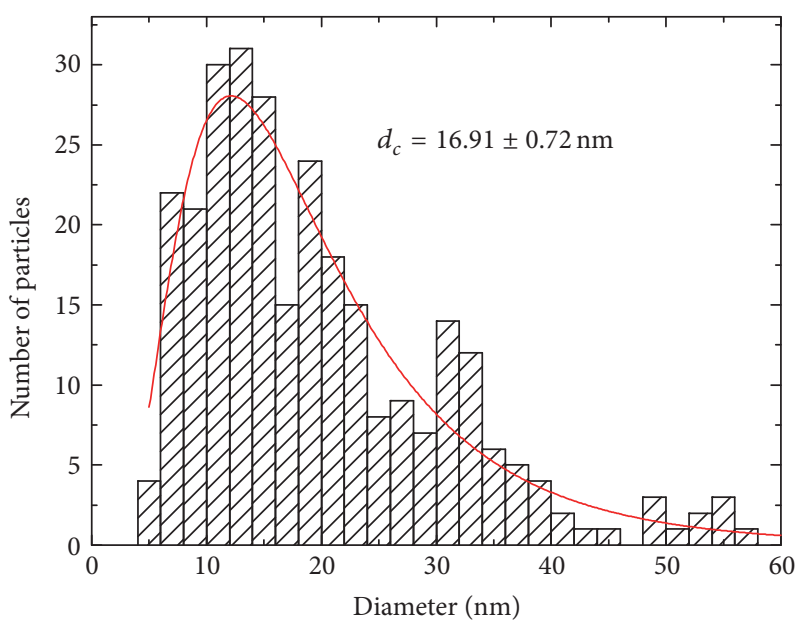

WII $\mathrm{DyF}_{3}$ sample \#2

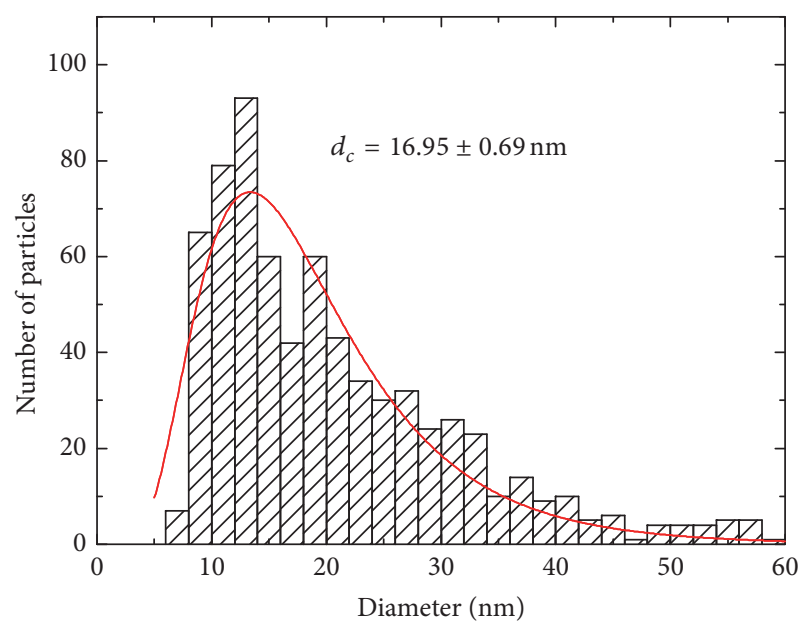

WII $\mathrm{DyF}_{3}$ sample \#1

(b)

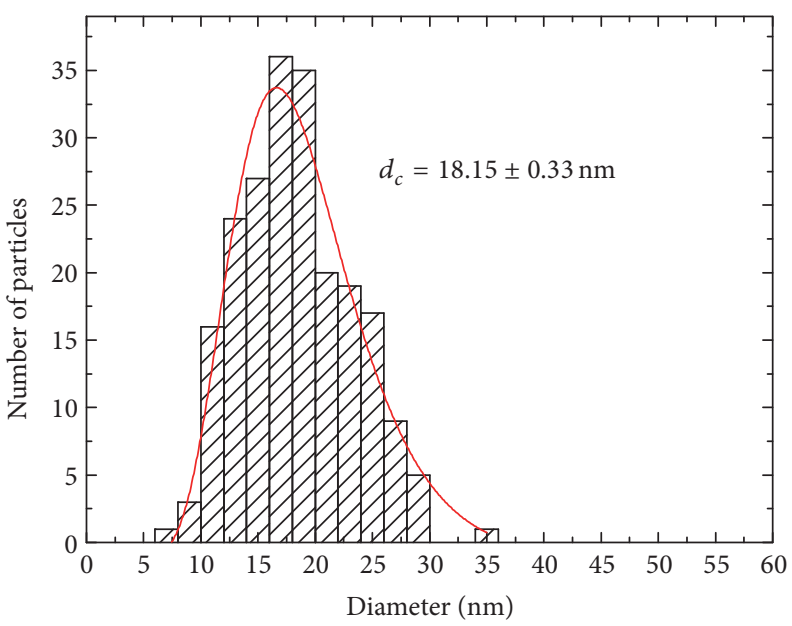

ZIJ $\mathrm{DyF}_{3}$ sample \#3

(c)

(d)

FIGURE 1: (a) TEM image of $\mathrm{DyF}_{3}$ nanoparticles with corresponding electron diffraction pattern in the insert (sample \#3). (b)-(d) The size distribution diagrams for all samples. Solid line is the log-normal distribution fitting, and $d_{c}$ is the center.

Then, after filtering, $4.75 \mathrm{~g}$ of sodium fluoride $\mathrm{NaF}(\mathrm{F}: \mathrm{Dy}=$ $3: 1)$ was added into the abovementioned solution under violent stirring. A white colloidal precipitate of $\mathrm{DyF}_{3}$ appeared immediately.

$$
\begin{aligned}
& \operatorname{Dy}\left(\mathrm{NO}_{3}\right)_{3}(\mathrm{aq})+3 \mathrm{NaF}(\mathrm{s}) \\
& \longrightarrow \mathrm{DyF}_{3}(\mathrm{~s})+3 \mathrm{NaNO}_{3}(\mathrm{aq})
\end{aligned}
$$

The $\mathrm{pH}$ of the suspension was adjusted by $25 \%$ ammonia aqueous solution (about 4.0-5.0). Deionized water was filled into the suspension to make the volume up to $750 \mathrm{~mL}$. After stirring for about $20 \mathrm{~min}$, the suspension was finally transferred into a $1 \mathrm{~L}$ round flask (synthesis of sample \#1 has been stopped at this stage). Part of the solution was placed into the microwave oven $(650 \mathrm{~W}, 2.45 \mathrm{GHz})$ for further hydrothermal treatment (sample \#2). The suspension was put into the microwave oven at $70 \%$ of the maximum power for 30 minutes. The resulting product was collected by centrifugation (Janetski K24; 12000 RPM) and washed using the deionized water for several times.

Finally, the solution was dried out on the flat surface in air at room temperature. Sample \#3 was prepared by the same method and treated by the microwave irradiation for 420 minutes.

TEM images of nanosized samples were obtained by using Philips CM300 operated at $300 \mathrm{kV}$ (Neel Institute, Grenoble, France). Powder X-ray diffraction was done by Bruker D8 Advance X-ray diffractometer with use of copper $\mathrm{Ka}(\alpha=$ $1.5418 \AA$ ) radiation and continuous scan (scan speed 0.005 degrees per second in the range of diffraction angles 20-60 degrees).

\section{Results and Discussion}

Figure 1 shows the TEM image with the corresponding electron diffraction pattern in the insert (sample \#3) and size 


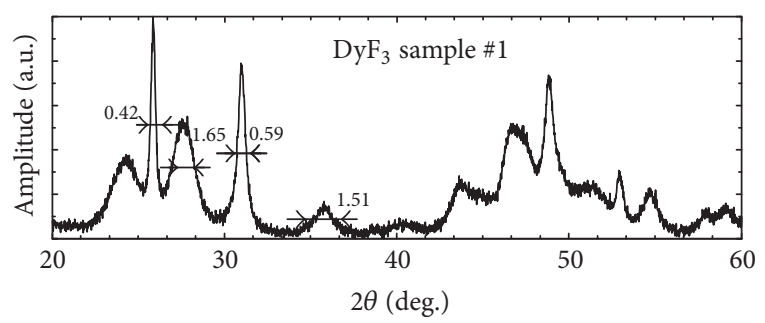

(a)

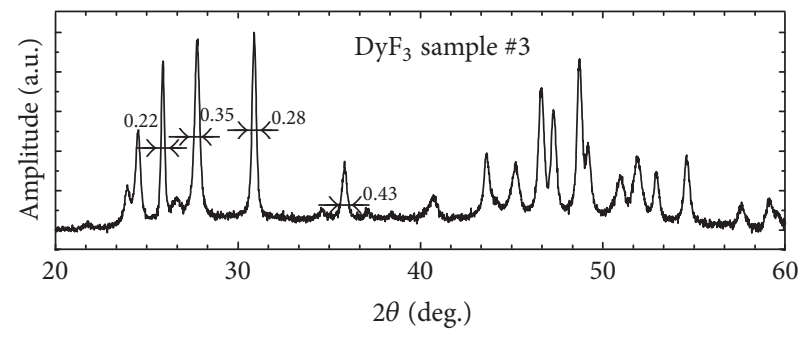

(c)

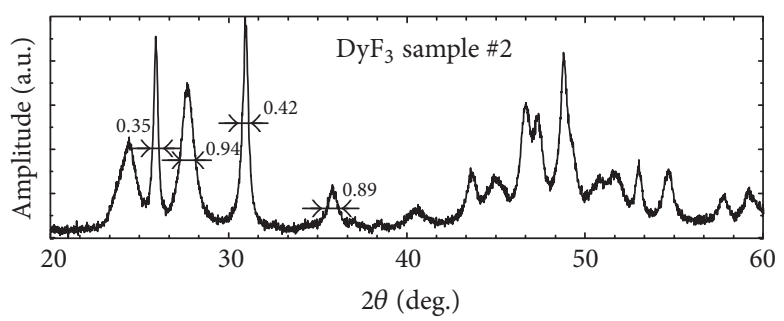

(b)

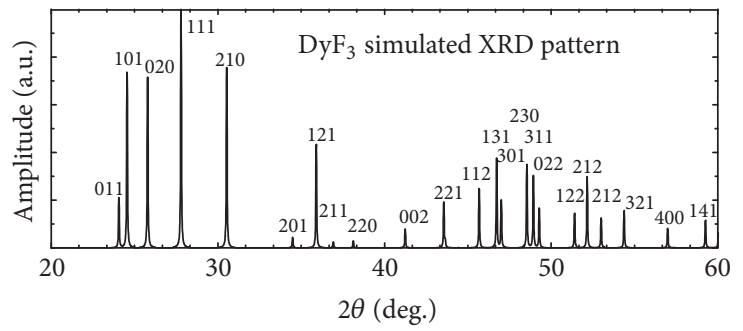

(d)

Figure 2: (a)-(c) Experimental XRD patterns of synthesized $\mathrm{DyF}_{3}$ nanosized samples \#1-3. (d) simulated XRD patterns in PowderCell software.

distribution diagrams for all samples. The sharp diffraction rings show the crystal particles presence (rings radii: $0.36 \mathrm{~nm}$, $0.32 \mathrm{~nm}$, and $0.20 \mathrm{~nm})$. All diagrams were fitted by the log-normal distribution. The synthesized nanoparticles have average size of about 16-18 nm (sample \#1, $16.9 \mathrm{~nm}$; sample $\# 2,16.9 \mathrm{~nm}$; sample \#3, $18.2 \mathrm{~nm}$ ). There is no significant $\mathrm{DyF}_{3}$ nanoparticles size dependence on the microwave-assisted hydrothermal treatment time unlike the case of $\mathrm{PrF}_{3}$ sample [20]. Clearly, the size distribution becomes narrower during the microwave irradiation. In the case of the microwaveassisted synthesis of $\mathrm{PrF}_{3}$ nanoparticles, the restructuring of particles was observed earlier by NMR [20]. It was interesting to see the crystal structure changes in the process of $\mathrm{DyF}_{3}$ nanosized samples treatment.

Crystal structure of $\mathrm{DyF}_{3}$ nanoparticles was characterized by X-ray diffraction (XRD). Experimental XRD patterns of three $\mathrm{DyF}_{3}$ nanosized samples are shown in Figure 2. Diffraction peaks could be indexed from the simulated pattern calculated by PowderCell [31] software (space group Pnma (No. 62), lattice constants $a=0.6460 \mathrm{~nm}, b=0.6906 \mathrm{~nm}$, and $c=0.4376 \mathrm{~nm}[32]$ ). Obviously, sample \#1 (Figure 2(a)) has wide peaks and after 30 minutes of the microwaveassisted hydrothermal treatment the peaks becomes narrower (Figure 2(b)). After 7 hours of treatment the XRD pattern became even narrower (Figure 2(c)). High and sharp peaks indicate high crystallinity of nanoparticles for sample \#3.

The analysis of obtained experimental data suggests the following hypothetical picture of the microwave-assisted hydrothermal modification process. Sample \#1 has many defects of crystal structure because of the explosive character of the colloidal reaction. Further microwave treatment of the colloidal solution leads to local heating of $\mathrm{DyF}_{3}$ particles. Some bigger particles crack into smaller ones, making the size distribution narrower, but the local restructuring continues further. The restructuring leads to decrease in the number of crystal structure defects.

The obtained results of restructuring process are different from that of $\mathrm{PrF}_{3}$ nanoparticles, where the weak size dependence [20] and absolutely no difference in XRD patterns were observed. One of the possible reasons for difference of the microwave-assisted hydrothermal treatment's results between $\mathrm{DyF}_{3}$ and $\mathrm{PrF}_{3}$ nanoparticles may be the different symmetry $\left(\mathrm{DyF}_{3}\right.$ - orthorhombic $D_{2 h}^{16}$-Pnma; $\mathrm{PrF}_{3}$ - hexagonal $\left.C_{6 v}^{3}-\mathrm{P}_{3} \mathrm{~cm}\right)$. Another reason could be the difference of lattice energies for lanthanide ions $\operatorname{Pr}$ and Dy [33].

The type of crystal structure defects is also different. In the case of $\mathrm{PrF}_{3}$ nanoparticles-point defects, for $\mathrm{DyF}_{3}$ nanoparticles - the defects are more severe. Annealing of the defects of the crystal structure of $\mathrm{DyF}_{3}$ nanoparticles leads to significant (2-5 times) narrowing of XRD peaks. Usually the width of XRD peaks is related to the nanoparticles size and microstrains. There are various methods of X-ray analysis such as Scherrer [34], Williamson-Hall [35], and WarrenAverbach [36] methods. The average nanoparticles size was calculated using Debye-Scherrer's formula:

$$
D=\frac{K \lambda}{\beta_{h k l} \cos \theta} .
$$

For synthesized $\mathrm{DyF}_{3}$ nanoparticles, the estimation gives too high values (ex., for sample \#3 $55 \mathrm{~nm}$ ), which supports the defect nature of XRD peaks linewidth.

The analysis of XRD pattern by Williamson-Hall method also gives too high values for the average size of nanoparticles and attempts to estimate lattice distortions do not give reliable results. Warren-Averbach analysis is suitable for resolved $\mathrm{XRD}$ peaks and in our case is not applicable. 


\section{Conclusions}

In summary, the series of $\mathrm{DyF}_{3}$ nanoparticles was successfully synthesized by the microwave-assisted colloidal hydrothermal method for the first time. The nanoparticles were characterized by TEM and XRD. The average size of particles is about $16-18 \mathrm{~nm}$ and the size distribution becomes narrower after the microwave treatment. It was observed that the microwave irradiation treatment strongly affects the width of XRD peaks. They become narrower with the microwave treatment. The defect-annealing model of the microwaveassisted hydrothermal modification process is suggested.

\section{Competing Interests}

The authors declare that they have no competing interests.

\section{Acknowledgments}

The work was performed according to the Russian Government Program of Competitive Growth of Kazan Federal University. E. M. Alakshin has been financially supported by the Russian Foundation for Basic Research (Project no. 16-3260155 mol_a_dk).

\section{References}

[1] F. Vetrone and J. A. Capobianco, "Lanthanide-doped fluoride nanoparticles: luminescence, upconversion, and biological applications," International Journal of Nanotechnology, vol. 5, no. 9-12, pp. 1306-1339, 2008.

[2] B. M. Tissue, "Synthesis and luminescence of lanthanide ions in nanoscale insulating hosts," Chemistry of Materials, vol. 10, no. 10, pp. 2837-2845, 1998.

[3] Z. G. Chen, H. L. Chen, H. Hu et al., "Versatile synthesis strategy for carboxylic acid-functionalized upconverting nanophosphors as biological labels," Journal of the American Chemical Society, vol. 130, no. 10, pp. 3023-3029, 2008.

[4] D. K. Chatterjee, A. J. Rufaihah, and Y. Zhang, "Upconversion fluorescence imaging of cells and small animals using lanthanide doped nanocrystals," Biomaterials, vol. 29, no. 7, pp. 937-943, 2008.

[5] P. R. Diamente, M. Raudsepp, and F. C. J. M. van Veggel, "Dispersible $\mathrm{Tm}^{3+}$-doped nanoparticles that exhibit strong $1.4 \mu \mathrm{m}$ photoluminescence," Advanced Functional Materials, vol. 17, no. 3, pp. 363-368, 2007.

[6] S. Sivakumar, P. R. Diamente, and F. C. J. M. van Veggel, "Silicacoated $\mathrm{Ln}^{3+}$-doped $\mathrm{LaF}_{3}$ nanoparticles as robust down-and upconverting biolabels," Chemistry-A European Journal, vol. 12, no. 22, pp. 5878-5884, 2006.

[7] X. Teng, Y. Zhu, W. Wei et al., "Lanthanide-doped $\mathrm{Na}_{\mathrm{x}} \mathrm{ScF}_{3+\mathrm{x}}$ nanocrystals: crystal structure evolution and multicolor tuning," Journal of the American Chemical Society, vol. 134, no. 20, pp. 8340-8343, 2012.

[8] V. Mahalingam, F. Vetrone, R. Naccache, A. Speghiniand, and J. A. Capobianco, "Colloidal $\mathrm{Tm}^{3+} / \mathrm{Yb}^{3+}$-doped $\mathrm{LiYF}_{4}$ nanocrystals: multiple luminescence spanning the UV to NIR regions via low-energy excitation," Advanced Materials, vol. 21, no. 40, pp. 4025-4028, 2009.
[9] S. Sarkar, C. Hazra, and V. Mahalingam, "Bright luminescence from colloidal $\mathrm{Ln}^{3+}$-doped $\mathrm{Ca}_{0.72} \mathrm{Y}_{0.28} \mathrm{~F}_{2.28}$ ( $\mathrm{Ln}=\mathrm{Eu}$, $\mathrm{Tm} / \mathrm{Yb}$ ) nanocrystals via both high and low energy radiations," Chemistry-A European Journal, vol. 18, no. 23, pp. 7050-7054, 2012.

[10] S. Sarkar, B. Meesaragandla, C. Hazra, and V. Mahalingam, "Sub-5 nm $\mathrm{Ln}^{3+}$-doped $\mathrm{BaLuF}_{5}$ nanocrystals: a platform to realize upconversion via interparticle energy transfer (IPET)," Advanced Materials, vol. 25, no. 6, pp. 856-860, 2013.

[11] H. Dong, S.-R. Du, X.-Y. Zheng et al., "Lanthanide nanoparticles: from design toward bioimaging and therapy," Chemical Reviews, vol. 115, no. 19, pp. 10725-10815, 2015.

[12] P. Rahman and M. Green, "The synthesis of rare earth fluoride based nanoparticles," Nanoscale, vol. 1, no. 2, pp. 214-224, 2009.

[13] L. Ma, W.-X. Chen, Y.-F. Zheng, J. Zhao, and Z. Xu, "Microwaveassisted hydrothermal synthesis and characterizations of $\mathrm{PrF}_{3}$ hollow nanoparticles," Materials Letters, vol. 61, no. 13, pp. 27652768, 2007.

[14] M. S. Tagirov, E. M. Alakshin, R. R. Gazizulin et al., "Spin kinetics of $3 \mathrm{He}$ in contact with synthesized $\mathrm{PrF}_{3}$ nanoparticles," Journal of Low Temperature Physics, vol. 162, no. 5-6, pp. 645652, 2011.

[15] E. M. Alakshin, B. M. Gabidullin, and A. T. Gubaidullin, "Development of various methods for PrF3 nanoparticles synthesis," https://arxiv.org/abs/1104.0208.

[16] E. M. Alakshin, A. S. Aleksandrov, A. V. Egorov, A. V. Klochkov, S. L. Korableva, and M. S. Tagirov, "Nuclear pseudoquadrupole resonance of 141Pr in Van Vleck paramagnet PrF3," JETP Letters, vol. 94, no. 3, pp. 240-242, 2011.

[17] E. M. Alakshin, D. S. Blokhin, A. M. Sabitova et al., "Experimental proof of the existence of water clusters in fullerene-like $\mathrm{PrF}_{3}$ nanoparticles," JETP Letters, vol. 96, no. 3, pp. 181-183, 2012.

[18] E. M. Alakshin, R. R. Gazizulin, A. V. Klochkov et al., "Size effect in the $\left(\mathrm{PrF}_{3}\right.$ nanoparticles- $\left.{ }^{3} \mathrm{He}\right)$ system," JETP Letters, vol. 97, no. 10, pp. 579-582, 2013.

[19] M. S. Pudovkin, S. L. Korableva, A. O. Krasheninnicova et al., "Toxicity of laser irradiated photoactive fluoride $\mathrm{PrF}_{3}$ nanoparticles toward bacteria," Journal of Physics: Conference Series, vol. 560, no. 1, Article ID 012011, 2014.

[20] E. M. Alakshin, R. R. Gazizulin, A. V. Klochkov et al., "Annealing of $\mathrm{PrF}_{3}$ nanoparticles by microwave irradiation," Optics and Spectroscopy, vol. 116, no. 5, pp. 721-723, 2014.

[21] A. M. Gazizulina, E. M. Alakshin, E. I. Baibekov et al., "Electron paramagnetic resonance of $\mathrm{Gd}^{3+}$ ions in powders of $\mathrm{LaF}_{3}: \mathrm{Gd}^{3+}$ nanocrystals," JETP Letters, vol. 99, no. 3, pp. 149-152, 2014.

[22] S.-E. Park, T.-H. Kim, S.-R. Lee, S. Namkung, and T.-S. Jang, "Effect of sintering conditions on the magnetic and microstructural properties of Nd-Fe-B sintered magnets doped with $\mathrm{DyF}_{3}$ powders," Journal of Applied Physics, vol. 111, no. 7, Article ID 07A707, 2012.

[23] X. J. Cao, L. Chen, S. Guo et al., "Coercivity enhancement of sintered Nd-Fe-B magnets by efficiently diffusing DyF3 based on electrophoretic deposition," Journal of Alloys and Compounds, vol. 631, pp. 315-320, 2015.

[24] S. Sawatzki, I. Dirba, L. Schultz, and O. Gutfleisch, "Electrical and magnetic properties of hot-deformed Nd-Fe-B magnets with different $\mathrm{DyF}_{3}$ additions," Journal of Applied Physics, vol. 114, no. 13, Article ID 133902, 2013.

[25] R. Sueptitz, S. Sawatzki, M. Moore, M. Uhlemann, O. Gutfleisch, and A. Gebert, "Effect of $\mathrm{DyF}_{3}$ on the corrosion behavior of hot-pressed Nd-Fe-B permanent magnets," Materials and Corrosion, vol. 66, no. 2, pp. 152-157, 2015. 
[26] Z. Duan, J. Zhang, and L. Hu, "Spectroscopic properties and Judd-Ofelt theory analysis of Dy ${ }^{3+}$ doped oxyfluoride silicate glass," Journal of Applied Physics, vol. 101, no. 4, Article ID 043110, 2007.

[27] A. V. Savinkov, S. L. Korableva, A. A. Rodionov et al., "Magnetic properties of $\mathrm{Dy}^{3+}$ ions and crystal field characterization in $\mathrm{YF}_{3}: \mathrm{Dy}^{3+}$ and $\mathrm{DyF}_{3}$ single crystals," Journal of Physics Condensed Matter, vol. 20, no. 48, Article ID 485220, 2008.

[28] X. Ye, J. Chen, M. Engel et al., "Competition of shape and interaction patchiness for self-assembling nanoplates," Nature Chemistry, vol. 5, no. 6, pp. 466-473, 2013.

[29] S. Bhowmik, T. Gorai, and U. Maitra, "A room temperature, templated synthesis of lanthanide trifluoride nanoparticles and their unusual self-assembly," Journal of Materials Chemistry C, vol. 2, no. 9, pp. 1597-1600, 2014.

[30] C. Li, J. Yang, P. Yang, H. Lian, and J. Lin, "Hydrothermal synthesis of lanthanide fluorides $\mathrm{LnF}_{3}$ ( $\mathrm{Ln}=\mathrm{La}$ to $\mathrm{Lu}$ ) nano/microcrystals with multiform structures and morphologies," Chemistry of Materials, vol. 20, no. 13, pp. 4317-4326, 2008.

[31] W. Kraus and G. Nolze, "POWDER CELL-a program for the representation and manipulation of crystal structures and calculation of the resulting X-ray powder patterns," Journal of Applied Crystallography, vol. 29, no. 3, pp. 301-303, 1996.

[32] DyF3 crystal structure, Springer Materials (electronic resource), http://materials.springer.com/isp/crystallographic/docs/sd 1300541.

[33] C. Dong, M. Raudsepp, and F. Van Veggel, "Kinetically determined crystal structures of undoped and $\mathrm{La}^{3+}$-doped $\mathrm{LnF}_{3}$," Journal of Physical Chemistry C, vol. 113, no. 1, pp. 472-478, 2009.

[34] P. Scherrer, "Bestimmung der Grösse und der inneren Struktur von Kolloidteilchen mittels Röntgenstrahlen," Nachrichten von der Gesellschaft der Wissenschaften zu Göttingen, vol. 26, pp. 98100, 1918.

[35] G. K. Williamson and W. H. Hall, "X-ray line broadening from filed aluminium and wolfram," Acta Metallurgica, vol. 1, no. 1, pp. 22-31, 1953.

[36] B. E. Warren and B. L. Averbach, "The separation of coldwork distortion and particle size broadening in X-ray patterns," Journal of Applied Physics, vol. 23, no. 4, p. 497, 1952. 

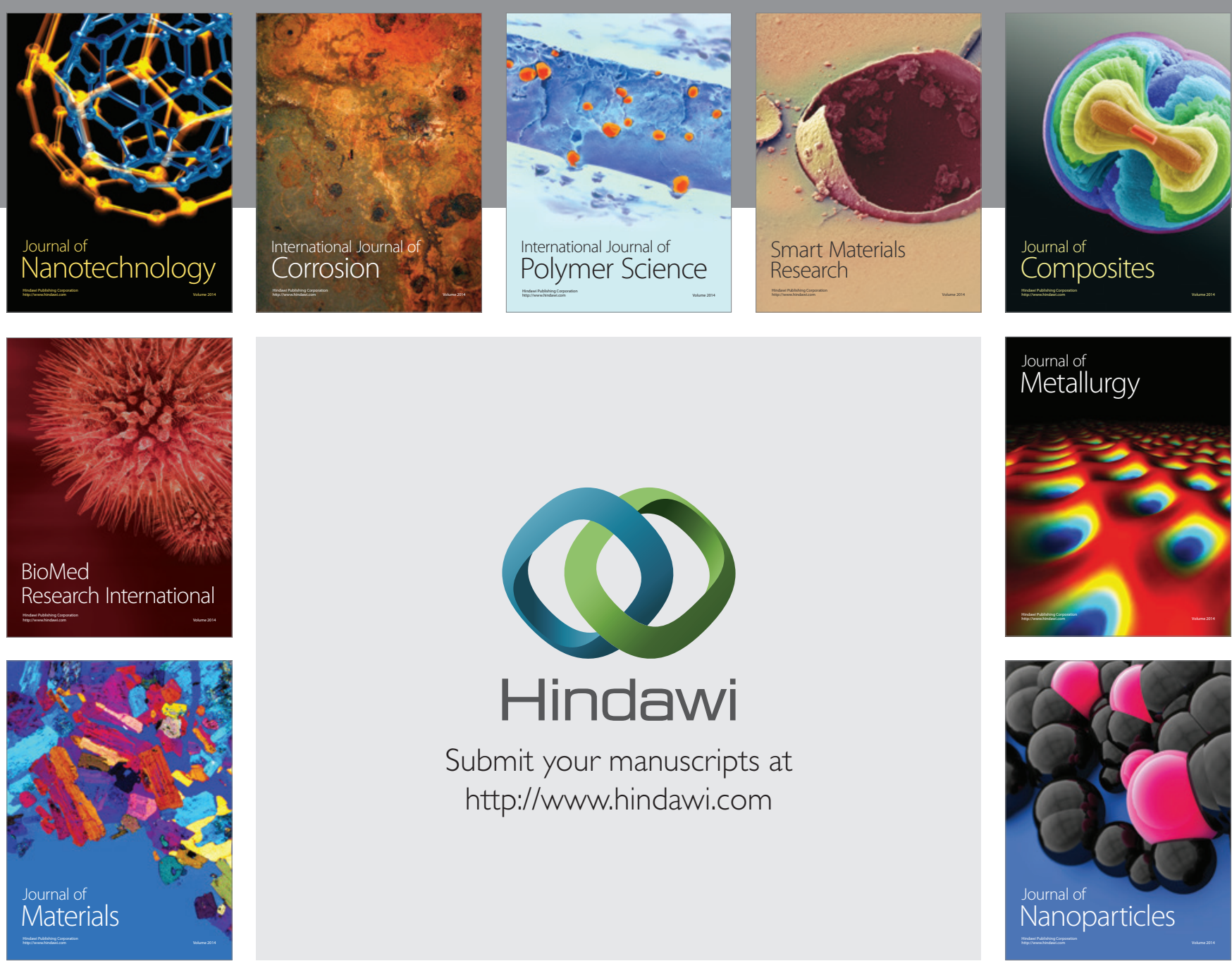

\section{Hindawi}

Submit your manuscripts at

http://www.hindawi.com

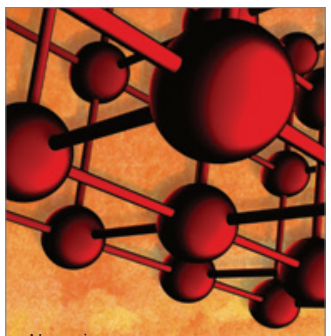

Materials Science and Engineering
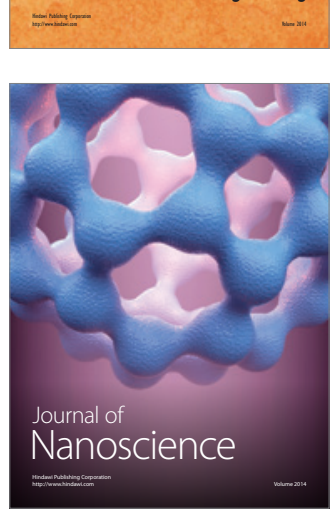
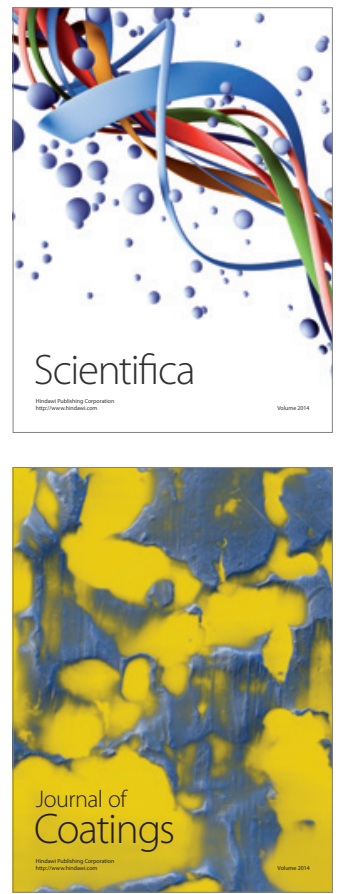
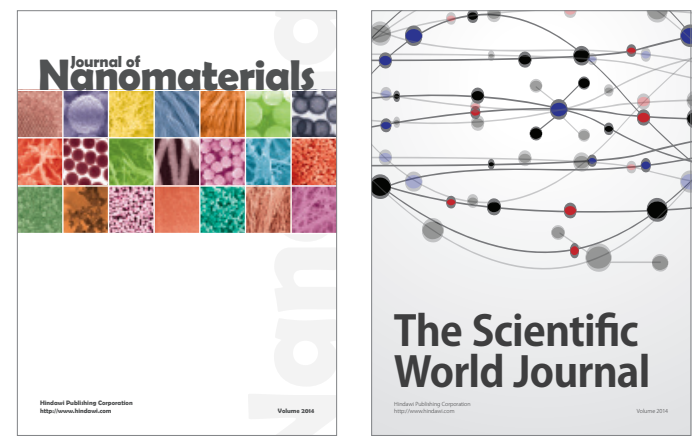

The Scientific World Journal
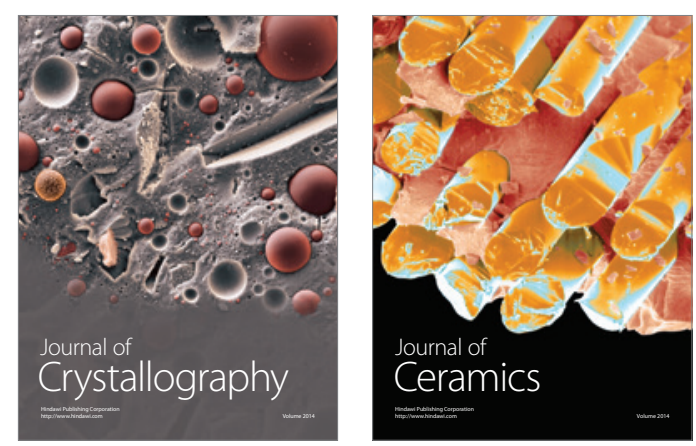
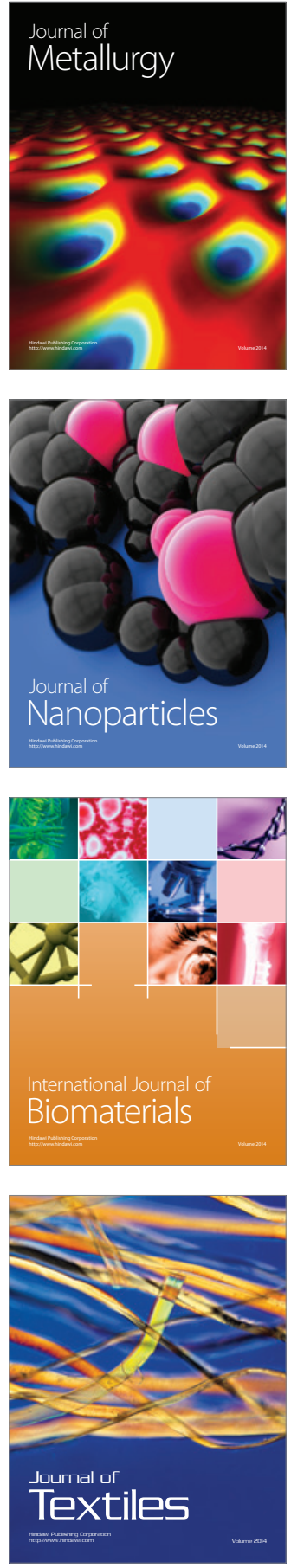